NBER WORKING PAPER SERIES

\title{
WHEN ARE FIXED EXCHANGE \\ RATES REALLY FIXED?
}

Andrés Velasco

Working Paper 5842

\section{NATIONAL BUREAU OF ECONOMIC RESEARCH \\ 1050 Massachusetts Avenue \\ Cambridge, MA 02138 \\ November 1996}

Earlier versions of this paper were presented at Princeton, Columbia, NYU, the Atlanta Fed, the World Bank, the Inter-American Macroeconomics Seminar, and the NBER IFM Winter Meeting. I am grateful to Guillermo Calvo, Alessandra Casella, Hal Cole, José de Gregorio, Allan Drazen, Sebastián Edwards, Ricardo Hausmann, Aart Kraay, Luisa Lambertini, Phil Lane, Paul Masson, Bob Mundell, Yaw Nyarko, Paolo Pesenti, Klaus Schmidt-Hebbel, Dani Rodrik, Ken Rogoff, Mariano Tommasi, Aaron Tornell and, especially, Roberto Chang for discussions and/or comments at different stages of this project. All errors are my own. A first draft of this paper was completed while I visited the Macroeconomic Adjustment and Growth Division of the World Bank, whose hospitality is gratefully acknowledged. Support was also provided by the Harvard-MIT RTG in Positive Political Economy and by the C.V. Starr Center for Applied Economics at NYU. This paper is part of NBER's research program in International Finance and Macroeconomics. Any opinions expressed are those of the author and not those of the National Bureau of Economic Research.

C) 1996 by Andrés Velasco. All rights reserved. Short sections of text, not to exceed two paragraphs, may be quoted without explicit permission provided that full credit, including $\mathbb{C}$ notice, is given to the source. 
When Are Fixed Exchange Rates Really Fixed?

Andrés Velasco

NBER Working Paper No. 5842

November 1996

JEL Nos. E52, F31, O23

International Finance and Macroeconomics

\title{
ABSTRACT
}

This paper analyzes the sustainability of fixed exchange rates by extending the Barro-Gordon framework to a fully dynamic context in which the level of a state variable (in this case debt) determines the payoffs available to the government at each point in time. The model yields the following results. If debt is sufficiently low, there is an equilibrium in which the government does not devalue. For an intermediate range of debt levels, the government devalues in response to an attack but not otherwise, so that self-fulfilling attacks can occur. Finally, for yet another debt range there can also be sunspot equilibria in which an attack (and the corresponding devaluation) occurs with positive probability.

\author{
Andrés Velasco \\ Department of Economics \\ New York University \\ 269 Mercer Street \\ New York, NY 10003 \\ and NBER \\ velasco@fasecon.nyu.edu
}




\section{Introduction}

Countries often fix their exchange rates and vow to keep them fixed forever, and then fail to deliver on such promises. Klein and Marion (1994) study a sample of 61 pegged exchange rate episodes in Latin America since the 1950s, and find that they have a mean duration of just 32 months. Obstfeld and Rogoff (1995) compile a list of all the countries that, as of June 1995, had kept fixed exchange rates against any currency for at least five years; they conclude that "...aside from some small tourism economies, oil sheikdoms, and highly dependent principalities, there is literally only a handful of countries that have continuously maintained tightly fixed exchange rates...." This stands in contrast to the many attempts at fixing rates, both in developed and developing economies. Particularly striking examples of the lack of viability of fixed rate regimes and the strength of speculative attacks against them were provided by the crisis of the European Monetary System in 1992-93 and the spectacular collapse of the Mexican peso's peg to the U.S. dollar in December 1994. Understanding why long-lasting and successful pegs are so rare remains one of the central questions of positive international finance. ${ }^{1}$

Two approaches can be distinguished in the academic literature on the subject. ${ }^{2}$ Using the labels coined by Jeanne (1994), there are "speculative attack" models, in which the collapse of a regime is determined by the exhaustion of the reserves available to defend the peg. The paradigm here is the model by Krugman (1979) and subsequent extensions. And there are also "cost-benefit" models in which the government can freely choose to devalue and renege on its previous pledges if the benefits of doing so outweigh the costs (typically, ongoing unemployment). The corresponding paradigm is the monetary policy game developed by Kydland and Prescott (1977) and Barro and Gordon (1983), repeatedly adapted to the open economy since. ${ }^{3}$

Neither approach seems fully satisfactory to explain recent collapses in places such as Europe and Mexico. Consider the latter case, described and

\footnotetext{
${ }^{1}$ As of September 1996, Argentina had sustained a fixed parity against the U.S. dollar for five-and-a-half years. Substantial real appreciation, and market turmoil in early 1995 and (less drastically) in July-August 1996, suggest that the survival of the so-called convertibility plan is far from guaranteed.

${ }^{2}$ Among the many useful recent surveys, see Agenor, Bhandari and Flood (1992), Obstfeld (1994) and Jeanne (1994).

${ }^{3}$ See Horn and Persson (1988) for an early application. For a more recent example, see Obstfeld (1991b).
} 
analyzed in Sachs, Tornell and Velasco (1996), among others. Capital inflows began drying up in March 1994, after the leading presidential candidate was assassinated; for the following nine months, during which a massive current account deficit had to be financed by drawing down reserves, the Mexican government could have taken corrective actions - a fiscal or monetary tightening, a devaluation, or some combination of the above- but failed to do so. A balance of payments crisis finally hit in December. The Krugman-type models, in which the government blindly follows an arbitrary monetary/exchange rule, is not helpful in analyzing the choices faced by policymakers in Mexico. Moreover -and unlike what is predicted by speculative attack models, in which speculators' purchases of all remaining reserves prompt the collapsethere seems to be no tight link between reserve exhaustion and the timing of a collapse. The Mexican government chose to give up when it still had U.S. $\$ 6$ billion in reserves and another U.S. \$6 billion in a swap agreement with the United States and Canada. This is even more striking in the European case, where several countries threw in the towel while they still had ample access to own and borrowed reserves. Such countries devalued because not doing so was too painful (in terms of high interest rates, unemployment, etc.) not because they were forced to devalue. For instance, Obstfeld (1994) stresses that Sweden abandoned its unilateral peg to ECU in November 1992 without an aggressive defense because the government had endured too much pain in fighting off another speculative attack earlier in the year.

The cost-benefit approach does provide an explicit account of the choices faced by a Central Bank that is contemplating devaluation, but fails in other crucial respects. Because models in this class are static (or at most allow for the same game to be repeated over time), they do not recognize that the trade-offs with which a government is confronted change as the state of the economy changes. For instance, the temptation to devalue is larger, ceteris paribus, the larger the current level of unemployment or the larger the stock of government debt. To the extent that such variables are persistent (today's unemployment rate may partially determine tomorrow's; the current stock of debt obviously affects future stocks through the government budget constraint), this calls for a dynamic game approach in which costs and benefits associated with given actions change as state variables evolve over time.

The same can be said about the issue of multiple equilibria. BarroGordon-type models can easily generate self-fulfilling attacks in a static context, but it is not clear that feature of the model necessarily survives in a dynamic context. Krugman (1996), for instance, has conjectured that once 
deteriorating fundamentals are reintroduced into a Barro-Gordon type of model, multiplicity disappears. "Cost/benefit" models à la Barro-Gordon also fail to capture the fact that clearly not all countries are equally vulnerable to self-fulfilling attacks, nor is any one country equally vulnerable at all points in time. For instance, Sachs, Tornell and Velasco (1996) argue that in the Mexican case self-fulfilling expectations became decisive only after the government ran down gross reserves and ran up short-term dollar debt. Hence, a satisfactory model must explain how and why multiple equilibria can occur for some levels of a relevant state variable (reserves, say, or debt) but not for others.

This paper develops a model in which elements of the "speculative attack" and "cost/benefit" approaches are brought together. In contrast to the former, a devaluation is always the result of a deliberate decision by an optimizing government. In contrast to the latter, dynamics matter, and the stock of accumulated debt determines whether the fixed rate is sustainable or not. Among the results are:

- If reputation matters and there is a fixed cost of devaluing, the peg is sustainable if and only if the stock of debt is sufficiently low. In this no-devaluation equilibrium debt is constant over time.

- There is a range of debt in which multiple equilibria occur: if agents expect the government will devalue today, the authorities will oblige; but if agents do not expect a devaluation, no devaluation will take place.

- For a certain range of debt sunspot equilibria can occur, in which a speculative attack (and a consequent devaluation) happen with positive probability. In these equilibria government optimally reduces the size of its debt over time.

Three additional references to the literature are in order. One paper so far to have placed state variables and dynamic issues at the center of the analysis of exchange rate pegs is Drazen and Masson (1994) -and in that sense it is clearly a forerunner of the work contained here. ${ }^{4}$ The focus of

\footnotetext{
${ }^{4}$ Velasco (1994) also deals with the question of currency crises in a dynamic context with state variables. The political economy questions studied, however, have little to do with either this paper or Drazen and Masson (1994).
} 
Drazen and Masson (1994), however, is quite different: in the context of imperfect information about how committed to low inflation a policymaker is, they ask whether sticking to a peg unambiguously enhances credibility and lowers expected devaluation. The answer is no: in the presence of a state variable (persistent unemployment in their case), a bad shock today that is not offset by devaluation may lead to a higher probability of devaluation tomorrow, and hence to higher rather than lower expected devaluation. Hence, a policymaker that acts tough may only weaken the perceived credibility of the announced policy.

Other closely related piece of work is by Cole and Kehoe (1995), who study debt crises. Once again, the focus is different: in the context of a nonmonetary model, they study under what conditions creditors' refusal to rollover debt may be self-fulfilling in the sense of forcing a debtor government into default. Yet one conclusion is common to that paper and this one: whether self-fulfilling crises can occur or not depends crucially on the accumulated level of debt.

Finally, there is the literature on fixed exchange rates as "discipline devices." Edwards (1995) presents econometric evidence showing that countries with fixed exchange rates in 1980 experienced lower inflation over the following decade than did countries with floating exchange rates in 1980. Tornell and Velasco (1995) present theoretical arguments and empirical evidence suggesting that -contrary to conventional wisdom-fixed exchange rates need not impose more fiscal discipline than do flexible rates. The debate is relevant, for only if fixed rates lead policy makers to adopt consistent macroeconomic policies can parities hope to survive over the long haul.

The paper is organized as follows. The next section sets up the basic model. The following two sections characterize government behavior and the associated losses under the benchmark cases of full discretion (and no political or reputational costs of devaluation) and fixed rates, respectively. Section 5 introduces reputational considerations and fixed devaluation costs, and computes a government's optimal surprise devaluation. Sections 6 through 8 examine whether and when these costs are sufficient to prevent a government that cannot precommit from devaluing, and construct assorted equilibria with and without devaluation. Section 9 concludes. 


\section{The Basic Model}

Consider an economy populated by a government and a private sector composed of many atomistic agents. The economy is fully characterized by the resource constraint

$$
b_{t+1}=R b_{t}+\theta\left(\pi_{t}^{e}-\pi_{t}\right)-x_{t}, \theta>0
$$

where $\pi$ is the actual rate of devaluation, $\pi^{e}$ is the expected rate, and $R$ is the world gross real rate of interest (assumed exogenous to the small open economy as a result of perfect capital mobility). Assume purchasing power parity and foreign prices constant and equal to one, so that the nominal exchange rate and the domestic price level are the same.

The constraint in 1 is subject to two interpretations. The first emphasizes the public finance problem of the government, and may be more appealing to neoclassically-minded readers. Under this interpretation, $b$ is the stock of net foreign liabilities of the consolidated government (including the Central Bank), and $x$ is the flow of government tax revenue. Assume purchasing power parity, so that the rate of inflation and nominal devaluation are the same. Then, the term $\theta\left(\pi_{t}-\pi_{t}^{e}\right)$ can be interpreted as inflation tax revenue, which falls with anticipated inflation (demand for money and therefore the tax base goes down) and increases with actual inflation (the tax rate goes up). ${ }^{5}$

The second interpretation emphasizes the role of real wages and the real exchange rate in the determination of the current account, and may appeal to readers with more Keynesian propensities. Under this interpretation, $b$ is the national net foreign liability position (including both government and private sector debts, and assumed always non-negative in what follows), and $x$ denotes an index of domestic aggregate demand (defined so that raising $x$ reduces the current account deficit, thereby curtailing the accumulation of foreign liabilities). The government is assumed to control aggregate demand by manipulating fiscal or monetary policy. The term $\theta\left(\pi_{t}^{e}-\pi_{t}\right)$ implies that nominal wage contracts are pre-set, so that whenever actual devaluation exceeds expected devaluation the real wage falls and the current account improves. In what follows I will use the language of the public finance inter-

\footnotetext{
${ }^{5}$ Recall that inflation and devaluation are the same in this context. The fact that fully anticipated inflation yields no revenue can be thought of as a normalization. Little changes if we assume otherwise.
} 
pretation, but readers should keep in mind that the alternative interpretation is also plausible.

Paths for $x$ and $\pi$ must be such that the following constraint is also satisfied

$$
\lim _{t \rightarrow \infty} b_{t} R^{-t} \leq 0
$$

which has the standard interpretation that debt cannot grow without bound.

The authorities' objective is to minimize, starting at each time $t$, the function

$$
\left(\frac{1}{2}\right) \sum_{s=t}^{\infty}\left(\alpha \pi_{s}^{2}+x_{s}^{2}\right) R^{-(s-t)}, \alpha>0
$$

which indicates that they dislike both devaluation and taxes (under the public finance perspective), or devaluation and aggregate demand contraction (under the alternative interpretation). ${ }^{6}$

The timing of actions is as follows. The economy leaves period $t-1$ with accumulated liabilities $b_{t}$, which are observable by all. The public moves first, setting its expectations of devaluation on the basis of the debt stock. Policy is set on the basis of $b_{t}$ and the public's move.

Throughout I will study only the realistic case in which the government cannot bind itself to a given course of action as of time 0 , but instead reoptimizes at every moment in time. In addition, I will restrict attention to Markovian strategies, in which actions at time $t$ depend only on the state (suitably defined) at time $t$. An equilibrium can therefore be defined as a pair of policy rules for the government ${ }^{7}$, and a rule for forming agents' expectations, such that and

a) the government minimizes 3 subject to 1 and 2 , as of each date $t \geq 0$,

b) expectations are realized.

This definition insures that the equilibrium is "sustainable" in the sense of Chari and Kehoe (1990) and "credible" in the sense of Stokey (1991). Individual agents behave competitively; the government behaves strategically, and the resulting strategies are best responses to each other starting at each subgame (thus, the equilibrium satisfies standard notions of sub-game perfection).

\footnotetext{
${ }^{6}$ The discount rate is assumed equal to the world interest rate, so that no anticipated debt accumulation or deccumulation should take place, except for strategic reasons.

${ }^{7}$ One for $\pi_{t}$ and one for $x_{t}$.
} 


\section{A Simple Discretionary Equilibrium}

This section characterizes the Markov-Nash equilibrium to the game in which the government acts with full discretion and no political costs of devaluing (or reputational considerations) are present.

What is the relevant state for the government's problem as of any time $t$ ? An obvious element is the inherited stock of commitments $b_{t}$. In addition, since (recall from above), the government moves after agents do, it can observe at each time $t$ what devaluation expectations are for that period. We can therefore define the government's state at time $t, s_{t}^{g}$, as $s_{t}^{g}=\left(b_{t}, \pi_{t}^{e}\right)$. In turn, the agents' state at time $t, s_{t}^{a}$, is simply $s_{t}^{a}=\left(b_{t}\right)$.

Because the problem is linear-quadratic, I postulate linear policy rules. Since debt is the only element in its state vector, the private sector sets its expectations of inflation using a rule of the form $\pi_{t}^{e}=\gamma R b_{t}$, where $\gamma$ is a policy coefficient to be endogenously determined. The public's policy rule implies that the resource constraint is

$$
b_{t+1}=(1+\theta \gamma) R b_{t}-\theta \pi_{t}-x_{t}
$$

so that, for a given $\gamma$, the future evolution of depends only on its current level and the government's actions. As a result, and with no loss of generality, we can make the government's policy rules functions of debt alone. Therefore, the government is assumed to use policy rules of the form $\pi_{t}=\beta R b_{t}$ and $x_{t}=\eta R b_{t}$ for all $t \geq 0$, where $\beta$ and $\eta$ are also policy coefficients to be endogenously determined. In equilibrium, of course, it must be the case that the public's rule for mapping debt into expected devaluation corresponds with the government's "true" mapping, so that $\gamma=\beta$.

The government's optimal rule is calculated by minimizing 3 as of each $t \geq 0$, subject to 1,2 , and the understanding that $\pi_{t}^{e}=\gamma R b_{t}$. This is a standard dynamic programming problem, the Bellman equation for which is

$$
L\left(b_{t}, \pi_{t}^{e}\right)=\operatorname{Min}\left\{\left(\frac{1}{2}\right)\left(\alpha \pi_{t}^{2}+x_{t}^{2}\right)+R^{-1} L\left(b_{t+1}, \pi_{t+1}^{e}\right)\right\}
$$

subject to 4 and the agents' expectational rule. First order conditions for this problem are

$$
\theta x_{t}=\alpha \pi_{t}
$$

and

$$
\pi_{t}=(1+\theta \gamma) \pi_{t+1}
$$


Notice that the policy function $\pi_{t}=\beta R b_{t}$ implies $\frac{\pi_{t+1}}{\pi_{t}}=\frac{b_{t+1}}{b_{t}}$. Using this expression in conjunction with $4,6,7$ and the equilibrium condition $\gamma=\beta$ we have that $\beta$ is given by the roots of the quadratic equation

$$
\beta^{2} R \alpha \theta+\beta R\left(\alpha-\theta^{2}\right)-(R-1) \theta=0
$$

Notice that one root is positive and the other negative, and only the positive one makes economic sense. ${ }^{8}$ It follows that the solution to the government's problem is given by a pair of policy rules of the form

$$
\pi_{t}=\beta R b_{t} \text { and } x_{t}=\eta R b_{t}=\left(\frac{\alpha}{\theta}\right) \beta R b_{t}
$$

where $\beta$ is indeed given by the positive root of 8 , and where $\eta=\left(\frac{\alpha}{\theta}\right) \beta$.

Hence, devaluation is positive in every period as long as debt is positive. The government, acting in a discretionary manner, attempts to use its informational advantage to reduce the outstanding stock of debt. Agents understand this, so that devaluation is all cost and no benefit. This is the well known cost of discretionary policy-making. The new result here is that this cost is not constant across time, but instead varies with the stock of debt.

Notice next that if we substitute 9 into 4 , requiring $\gamma=\beta$, we obtain

$$
b_{t+1}=b_{t}(1+\theta \beta)^{-1}<b_{t}
$$

so that the government runs a fiscal surplus and debt falls over time. Recall that the standard Barro (1979) rule for the management of the public debt states that if the rate of interest equals the rate of discount, and if current non-interest government income equals permanent income (both of which hold here), then debt should be constant. That standard rule fails in the present context. The reason is simple: since devaluation expectations depend on the stock $b_{t}$ via the term $(1+\theta \beta)$, the perceived return on savings (from the government's point of view) is $(1+\theta \beta) R$, which is larger than the discount rate $R$. As a result, government savings is positive along the equilibrium path, and government debt falls. The reduction in debt allows the government to reduce devaluation expectations over time. ${ }^{9}$

\footnotetext{
${ }^{8}$ The negative root makes no economic sense because unanticipated negative devaluation would produce negative revenue (and, ceteris paribus, increase debt) while at the same time creating a utility loss.

${ }^{9} \mathrm{~A}$ similar result was first obtained by Obstfeld (1991a). See also Calvo and Guidotti (1990).
} 
Finally, using the first-order conditions 6 and 7 and policy rule 9 in the objective function we can compute the policy loss along this equilibrium:

$$
L^{*}\left(b_{t}, \beta R b_{t}\right)=\left(\frac{1}{2}\right)\left(\frac{R-1}{R}\right) \psi\left(R b_{t}\right)^{2}
$$

where the superscript " $s$ " stands "for simple" and where $\psi \equiv\left(\frac{R}{R-1}\right)\left(\frac{\alpha}{\theta^{2}}\right) \theta \beta(1+\theta \beta)=$ $1+\theta \beta\left(\frac{R}{R-1}\right)>1$. Notice that the higher is $\beta$-that is, the higher the rate of devaluation implemented in equilibrium- the larger is $\psi$ and therefore the loss. If $\beta=0, \psi=1$.

The following summarizes the results of this section:

Proposition 1 If the government acts with discretion, and no fixed costs of devaluation or reputational considerations are present,

a) it implements a positive rate of devaluation that is proportional to the outstanding stock of debt: $\pi_{t}^{d}=\beta R b_{t}$ for all $t$; and

b) it drives debt asymptotically down to zero: $b_{t+1}=b_{t}(1+\theta \beta)^{-1}$ for all $t$.

\section{Fixed Exchange Rates}

For purposes of comparison, consider now the implications of the following rule: irrevocably fixed exchange rates, so that $\pi_{t}=0 \forall t$. As long as the rule is credible (and I assume until further notice that it is), agents set $\pi_{t}^{e}=0$, so that $\theta\left(\pi_{t}^{e}-\pi_{t}\right)=0 \forall t$. Because the rate of discount in 3 is equal to the rate of interest, it is clear that there is no incentive for expected accumulation or deccumulation of debt. This means that $x$ must be set according to a simple policy rule:

$$
x_{t}=\left(\frac{R-1}{R}\right) R b_{t} \forall t,
$$

which is equivalent to saying that government revenues must be equal to the government's "expected permanent outlays" in every period of time. As a result, the policy loss as of any time $t$ is

$$
L^{f}\left(b_{t}, 0\right)=\left(\frac{1}{2}\right)\left(\frac{R-1}{R}\right)\left(R b_{t}\right)^{2}
$$

which is obtained simply by substituting the expression for $x_{t}$ into 3 and setting $\pi=0$ for all time, and where the superscript $f$ stands for "fixed." 
Does a fixed exchange rate provide higher welfare than a fully discretionary regime? Using 13 and 11 we see that

$$
L^{s}\left(b_{t}, \beta R b_{t}\right)-L^{f}\left(b_{t}, 0\right)=\left(\frac{1}{2}\right)\left(\frac{R-1}{R}\right)(\psi-1)\left(R b_{t}\right)^{2}=\left(\frac{1}{2}\right) \theta \beta\left(R b_{t}\right)^{2}>0
$$

We therefore have:

Proposition 2 (Superiority of Fixed Exchange Rates) A fixed exchange rate unambiguously lowers losses.

This result, which simply extends to a dynamic context the superiority of rules versus discretion first advocated by Kydland and Prescott (1977), derives straightforwardly from the fact that a commitment to fix overcomes the time inconsistency problem. The unambiguous superiority of a noncontingent rule was to be expected in this non-stochastic setting, for the credibility-flexibility trade-off stressed by Rogoff (1985) is absent.

\section{Costs of Devaluation and The Effects of Reputation}

How can incentives be created for the government to stick to a path of fixed rates, given that in reality unbreakable commitments to fix (or to follow any announced policy, for that matter) simply do not exist? An obvious answer is to introduce costs associated with setting a non-zero rate of devaluation. That is what this section does, and the following ones characterize the corresponding equilibria.

Before that, a bit of jargon is necessary. We have seen that in this model devaluation can either be zero or can be given by $\pi_{t}=\beta R b_{t}>0$. In this spirit, I define a speculative attack as a sudden increase in expected devaluation from $\pi_{t}^{e}=0$ to $\pi_{t}^{e}=\beta R b_{t}$. From budget constraint 1 , it is clear that such a change reduces money demand and, ceteris paribus, increases the total financial commitments government faces as of period $t$-and hence is akin to the speculative attacks we observe in the real world.

Following Obstfeld (1991b), Cukierman, Kiguel and Leiderman (1994), and Ozkan and Sutherland (1994 and 1995), among many others, assume the policymaker faces a fixed cost (in utility terms) the first time she devalues after having promised fixed rates forever. The magnitude of this cost depends 
on circumstances -in particular, on whether or not the devaluation is in response to a speculative attack. The cost is $c>0$ if the policymaker devalues without being subject to a speculative attack. If she is subject to an attack and as a result devalues, she pays $k$, where $0<k<c$. This assumption is realistic: governments that commit to a peg and then renege on the promise typically face costs -loss of pride, voter disapproval, maybe even removal from office- that need not be proportional to the size of the devaluation or to any other macroeconomic variable. At the same time, the political stigma associated with devaluation is less if it is done in response to turmoil (as several the European countries did in the midst of the EMS crisis, at a surprisingly small political cost) than if it is done with no apparent cause, so that the government can reasonably be suspected of cheating.

In addition, henceforth I allow for strategies in which reputational considerations are present. In particular, assume that, if a devaluation is ever observed (say, at time $t$ ), the policymakers suffers a complete loss of reputation: thereafter and forever, the discretionary rate of devaluation is expected by agents: $\pi_{s}^{e}=\beta R b_{s} \forall s>t$. As a result, the economy reverts to the equilibrium characterized in section 3 above. This assumption is of course analogous to that of trigger strategies, first employed in a similar but static context by Barro and Gordon (1983).

The additional elements introduced in this section require that we enlarge the state space that is relevant for each player. The history of play now matters. Define the indicator variable $d_{t}$ where $d_{t}=0$ if $\pi_{t}=0 \forall s<t$, and $d_{t}=1$ otherwise. Then, the relevant state for the agents is given by $s_{t}^{a}=\left(b_{t}, d_{t}\right)$. Private agents' strategies are now Markovian in this enlarged state-space: at the start of period $t$, given $b_{t}$ and $d_{t}$, agents set $\pi_{t}^{e}$. In particular, if the government has set $\pi_{s}>0$ for any $s<t$, so that $d_{t}=1$, agents set $\pi_{t}^{e}=\beta R b_{t} .^{10}$

The state space for the government must also be enlarged. We can define the government's state at time $t$ as $s_{t}^{g}=\left(b_{t}, \pi_{t}^{e}, d_{t}\right)$, where $\pi_{t}^{e}=0$ or $\pi_{t}^{e}=$ $\beta R b_{t}$ are the only two possible values for $\pi_{t}^{e}$, and $d_{t}$ can take on the values of 0 or 1 as before. Of course, given the expectational mechanism established above, $\pi_{t}^{e}=\beta R b_{t}$ whenever $d_{t}=1$.

Suppose that after having announced $\pi=0$ forever, the government

\footnotetext{
${ }^{10}$ Reputational constraints of this sort are seldom introduced into full-fledged dynamic games such as this one. For instances where it has been done, see Benhabib and Velasco (1996) and Benhabib, Rustichini and Velasco (1996).
} 
nonetheless chooses to devalue. Two things must be determined. First, what is the optimal surprise devaluation? Second, what is the loss associated with such a deviation from the promise made earlier?

If the government unexpectedly devalues at time $t$, its loss (exclusive of any fixed costs) is

$$
L^{d}\left(b_{t}, 0,0\right)=\operatorname{Min}\left(\frac{1}{2}\right)\left\{\left(x_{t}^{2}+\alpha \pi_{t}^{2}\right)+\frac{L^{d}\left(b_{t+1}, \beta R b_{t+1}, 1\right)}{R}\right\}
$$

where the superscript $d$ stands for "devaluation," and where $L^{d}\left(b_{t+1}, \beta R b_{t+1}, 1\right)=$ $\left(\frac{1}{2}\right) \psi\left(\frac{R-1}{R}\right) R^{2}\left[R b_{t}-\pi_{t}-x_{t}\right]^{2}$ follows from 1 and 11 . First order conditions are

$$
\begin{gathered}
x_{t}=\psi\left(\frac{R-1}{R}\right) R b_{t+1} \\
\alpha \pi_{t}=\theta x_{t}
\end{gathered}
$$

Combining these two with the budget constraint $b_{t+1}=R b_{t}-\theta \pi_{t}-x_{t}$, we can solve for the optimal surprise devaluation:

$$
\pi_{t}=\left(\frac{\beta}{1+\theta \beta}\right) R b_{t}
$$

Notice, comparing 9 and 18, that for a same $b_{t}$ the rate of devaluation is larger under the discretionary regime than under a surprise. That is because in the case of 9 the devaluation is anticipated, so that positive devaluation expectations make total government financial commitments equal to $(1+\theta \beta) R b_{t}$, while in the case of 18 the surprise nature of the devaluation means that total government commitments as of time $t$ are simply $R b_{t}$.

Using 18 in 17, and recalling that a surprise devaluation (i.e., one that was not motivated by a speculative attack) induces a utility loss of $c$, we have:

$$
L^{d}\left(b_{t}, 0,0\right)=\left(\frac{1}{2}\right)\left(\frac{R-1}{R}\right)\left(\frac{1}{1+\theta \beta}\right)^{2} \psi\left(R b_{t}\right)^{2}+c
$$

Equation 19 has an interpretation closely related to the discussion in the previous paragraph: because the devaluation is unanticipated, the loss in 19 (abstracting from fixed costs) is smaller than the loss in 11 by the factor $(1+\theta \beta)^{-2}$

\footnotetext{
"Of course, the term $(1+\theta \beta)^{-1}$ is squared because utility is quadratic.
} 


\section{No Devaluation Equilibrium}

We are now in a position to ascertain whether and when a policy of fixing is made sustainable by the assorted costs of devaluing. Consider first the case in which no speculative attack has taken place at the start of period $t$, and no speculative attack is expected in the future either, and ask under what conditions this is an equilibrium. In the sections that follow, by contrast, I construct equilibria in which speculative attacks a) can happen but are assigned zero probability by the government, and b) happen with positive probability, and the government assigns the "right" probability to their future occurrence.

In this and the following sections, I verify that proposed strategy profiles give rise to sub-game perfect equilibria by recourse to the "one-shot deviation principle." That is, in what follows it suffices to check whether there are any circumstances (more precisely, levels of the state vector) where a player can gain by deviating from the proposed strategy profile for one period and returning to it thereafter. If no such profitable "one-shot deviations" exist, then proposed strategy profile is sub-game perfect. ${ }^{12}$

Consider now the case of a period $t$, to which corresponds a level of debt $b_{t}$, in which agents set $\pi_{t}^{e}=0$. Given the fact that no attack has occurred or is expected, if the authorities decide to stick to the fixed rate their optimal fiscal policy is to set $x_{t}=\left(\frac{R-1}{R}\right) R b_{t} \forall t$. In this case, the loss is given by the corresponding version of 13 :

$$
L^{\text {nd }}\left(b_{t}, 0,0\right)=\left(\frac{1}{2}\right)\left(\frac{R-1}{R}\right)\left(R b_{t}\right)^{2}
$$

where "nd" stands for "no devaluation." If instead they foist a surprise devaluation on the public, their loss is given by 19 . Using these expressions we see that

\footnotetext{
${ }^{12}$ The "one-shot deviation principle" is essentially equivalent to the principle of optimality in dynamic programming. For a lucid discussion of why and under what conditions considering one-shot deviations is enough to establish that a strategy profile is sub-game perfect see Fudenberg and Tirole (1992), section 4.2, pp. 108-110. Techically, in an infinite horizon setup, for the "one-shot deviation principle" to apply the game must be "continuous at infinity," meaning that payoffs in the distant future are relatively unimportant. It is easy to check that requirement is met by the game under study here.
} 


$$
L^{\text {nd }}\left(b_{t}, 0,0\right)-L^{d}\left(b_{t}, 0,0\right)=\left(\frac{1}{2}\right)\left(\frac{R-1}{R}\right)\left(1-\frac{\psi}{(1+\theta \beta)^{2}}\right)\left(R b_{t}\right)^{2}-c
$$

If $\psi \geq(1+\theta \beta)^{2}$, expression 21 is non-positive, and it never pays off for the government to foist a surprise devaluation on the public. ${ }^{13}$ But if $\psi<$ $(1+\theta \beta)^{2}$, the temptation to devalue overwhelms the policymaker as long as debt is sufficiently large and/or $c$ is sufficiently small. Figure 1 depicts this situation.

Recalling the definition of $\psi \equiv 1+\theta \beta\left(\frac{R}{R-1}\right)$, it is straightforward to check that which case obtains depends, in fact, on parameter values: $\psi<(1+\theta \beta)^{2}$ if $\left(\frac{1}{R-1}\right)<1+\theta \beta$, which may or may not hold. Henceforth I assume the "interesting" case of $\psi<(1+\theta \beta)^{2}$, so that -in spite of reputation and of fixed costs of devaluing - the peg will be abandoned for high stocks of debt.

Let $\bar{b}$ be the level of debt that sets 21 equal to zero, where it is straightforward to calculate that

$$
\bar{b}=(1+\theta \beta)\left(\frac{1}{(1+\theta \beta)^{2}-\psi}\right)^{1 / 2}\left(\frac{2 c}{(R-1) R}\right)^{1 / 2}
$$

Notice that if $b \leq \bar{b}$, the government's beliefs that were necessary to conclude that the loss associated with continued fixing is given by 13 are indeed selffulfilling: if the government does not devalue today, the stock of debt in the following period is the same; therefore, if it did not pay off to devalue today, it will not pay off to do so in the future either. Hence, there is no reason why agents should expect a positive rate of devaluation in the future. In short, we have:

Proposition 3 (No-Devaluation Equilibria) There exists a no-devaluation equilibrium in which $\pi_{t+s}=\pi_{t+s}^{e}=0 \forall s \geq 0$, and debt is constant at $b_{t}$ forever, if

a) Parameters are such that $\psi \geq(1+\theta \beta)^{2}$.

b) Parameters are such that $\psi<(1+\theta \beta)^{2}$, and in addition $b_{t} \leq \bar{b}$.

\footnotetext{
${ }^{13}$ Notice that in this case the government would never devalue even if $c=0$.
} 


\section{Self-Fulfilling Equilibria When No Attacks Are Expected in the Future}

So far we have assumed that, if time $t$ is the current period, $\pi_{t}^{e}=0$. Consider, conversely, what happens if there is a speculative attack at time $t$, but -if the government resists the temptation to devalue in response to the attack at $t$ there is a zero probability of such an attack ever occurring again. This can be interpreted as a case in which speculative attacks are "rare events" in the country in question (Switzerland?), or in which the attack was motivated by some circumstance (a political shock such as the assassination of presidential candidate in Mexico in March 1994?) that is not expected to be repeated. More formally, this setup can be interpreted as the limiting case (when the probability of an attack goes to zero) of the sunspot equilibrium described in the next section. ${ }^{14}$

If there is an attack at time $t$, what will agents' expectations of devaluation be? If debt at that time is $b_{t}$, then we know from our previous analysis (see equation 9 or, equivalently, 18) that a government that chooses to devalue optimally sets $\pi_{t}=\beta R b_{t}$. Understanding this the public, if expecting a devaluation, sets $\pi_{t}^{e}=\beta R b_{t}$. Therefore the consequence of the speculative attack (recall budget constraint 1 ) is to increase government commitments from $R b_{t}$ to $(1+\theta \beta) R b_{t}$.

Focus now on the choices faced by the government. Recall that the government expects that, if it does not devalue at $t$, agents will expect $\pi_{s}^{e}=0$ for all $s>t$. In that case, if it continues to fix in spite of the attack, it obviously should follow the previously derived fiscal policy of smoothing the tax burden intertemporally, so that its loss is

$$
L^{n d}\left(b_{t}, \beta R b_{t}, 0\right)=\left(\frac{1}{2}\right)\left(\frac{R-1}{R}\right)(1+\theta \beta)^{2}\left(R b_{t}\right)^{2}
$$

Notice that if at the start of period $t$ the inherited stock of debt was $b_{t}$, at the start of $t+1$ it will be $(1+\theta \beta) b_{t}$. We know from the previous section that a no-devaluation equilibrium occurs if debt levels are no larger than $\bar{b}$. Hence, for the government's expectation of no attacks in the future to be rational, we must have $b_{t} \leq(1+\theta \beta)^{-1} \bar{b}$.

\footnotetext{
${ }^{14}$ For a discussion of an equilibrium analogous to that constructed in this section, see section 5 of Cole and Kehoe (1995).
} 
If it chooses to devalue in response to the attack, on the other hand, the government's loss is given by

$$
L^{d}\left(b_{t}, \beta R b_{t}, 0\right)=\left(\frac{1}{2}\right)\left(\frac{R-1}{R}\right) \psi\left(R b_{t}\right)^{2}+k
$$

It follows that

$$
L^{n d}\left(b_{t}, \beta R b_{t}, 0\right)-L^{d}\left(b_{t}, \beta R b_{t}, 0\right)=\left(\frac{1}{2}\right)\left(\frac{R-1}{R}\right)\left((1+\theta \beta)^{2}-\psi\right)\left(R b_{t}\right)^{2}-k
$$

Let $\tilde{b}$ be the stock of debt that sets 25 equal to zero. It is easy to calculate that

$$
\tilde{b}=\left(\frac{1}{(1+\theta \beta)^{2}-\psi}\right)^{1 / 2}\left(\frac{2 k}{(R-1) R}\right)^{1 / 2}<\bar{b}
$$

These results can be summarized as:

Proposition 4 (Self-Fulfilling Collapse When No Future Attacks Are Expected) If $\psi<(1+\theta \beta)^{2}, \widetilde{b}<b_{t} \leq(1+\theta \beta)^{-1} \bar{b}$, and in addition no attacks are expected at times $s>t$ if there is no devaluation at $t$, we have two possible outcomes:

a) If no speculative attack takes place at time $t$, no devaluation takes place at that time either. Debt is stationary at $b_{t}$ thereafter.

b) If a speculative attack happens at time $t$ we have a devaluation equilibrium in which $\pi_{t}=\pi_{t}^{e}=\beta R b_{t}$, even though there is a zero probability of such an attack ever occurring again should the government resist the temptation to devalue at time $t$. In future periods (after the devaluation), variables behave as specified in Proposition 3.1.

Hence, for a certain range of debt, loss of faith on the part of the private sector -even if the government does not expect that loss of faith ever to happen again-can trigger a devaluation. The range of debts for which this can happen is depicted in Figure 2. We have, then, a case of possible selffulfilling expectations.

Of course, the existence of self-fulfilling attacks is not news to anyone who has followed the recent literature. Many authors -Obstfeld (1986, 1991b and 1994), de Kock and Grilli (1993), Ozkan and Sutherland (1994 and 1995), and Bensaid and Jeanne (1994a and b), among others - have stressed that the behavior of optimizing governments lacking access to a precommitment 
technology can lead to multiplicity of equilibria. What is new in this example is twofold. Formally, multiplicity is derived in an optimizing and fully dynamic setting. Substantively, it shows that multiplicity is possible for some levels of debt (or some relevant state variable), but not for others. Hence it suggests a reason why (in accordance with one's natural intuition about the real world) why not all countries are equally vulnerable to self-fulfilling attacks at a given time, nor is any one country equally vulnerable at all points in time.

\section{Sunspot Equilibria}

The example of the previous section is somewhat special. This section shows there may be multiple equilibria in other circumstances and for more general structures of beliefs. Consider the case in which investors' behavior follows a sunspot: at each time $t$, they engage in a speculative attack with constant probability $p$. In what follows I investigate under what conditions there exists an equilibrium with this property, in that the government responds to an attack with a devaluation, but retains the peg otherwise.

To simplify matters considerably, in what follows I assume $k=0$. The reason for this assumption is essentially technical: we shall see below that a government that faces a positive probability of collapse in the future will optimally choose to reduce debt today. But if there is a lower bound on debt below which self-fulfilling attacks are not possible, then debt reduction need not go beyond this point. This means that fiscal policy in the period while debt is being reduced is not stationary (the ratio $x_{t} / R b_{t}$ is not constant) and that therefore loss functions cannot be written in closed form. If $k$ were "small" and debt at first sufficiently "high", it would take a long time for debt to converge to that lower bound. The analysis that follows can be thought of as an approximation to that case.

I proceed in the following way. First, I compute the expected losses under the proposed equilibrium path. In particular, this requires that we characterize the optimal fiscal policy for a government that does not choose to devalue, and compute the associated loss. ${ }^{15}$ Then, we can ascertain whether one-shot deviations from the proposed path are profitable; if they are not, then we have an equilibrium.

\footnotetext{
${ }^{15}$ The losses associated with devaluing, with or without a previous attack, have been already computed in sections 3 and 5 above.
} 
In order to determine the optimal fiscal policy in this environment, a government that does not devalue after not being attacked at time $t$ must solve the following problem:

$$
\begin{aligned}
L^{n d}\left(b_{t}, 0,0\right)= & \operatorname{Min}\left\{\left(\frac{1}{2}\right) x_{t}^{2}+p R^{-1} L^{d}\left(b_{t+1}, \beta R b_{t+1}, 0\right)\right. \\
& \left.+(1-p) R^{-1} L^{n d}\left(b_{t+1}, 0,0\right)\right\}
\end{aligned}
$$

where $L^{d}\left(b_{t+1}, \beta R b_{t+1}, 0\right)$ is given by 24 with $k=0$, subject to

$$
b_{t+1}=R b_{t}-x_{t}
$$

The corresponding Euler equation is

$$
x_{t}=(1-p) x_{t+1}+p(R-1) \psi b_{t+1}
$$

which, along with 28 and the standard transversality and solvency conditions, fully determine the evolution of the system (as long there is no attack).

In this infinite horizon economy, it is straightforward to show that the above optimality conditions imply a fiscal policy function of the form

$$
x_{t}=\rho R b_{t}
$$

where $\rho$ is equal to the single positive root of the quadratic equation

$$
\rho^{2} R(1-p)+\rho[1-R(1-p)+p \psi(R-1)]-p \psi(R-1)=0
$$

so that $\rho=\left(\frac{R-1}{R}\right)$ if $p=0$, as one would expect, and $\rho=\left(\frac{\psi(R-1)}{1+\psi(R-1)}\right)$ if $p=1$. It is also easy to see (and intuitive enough) that $\rho$ rises with $p$ : the higher the probability of a collapse in the future, the more the government should tax and reduce debt today.

As a result, along such a path debt follows

$$
b_{t+1}=R(1-\rho) b_{t}
$$

Since $\rho>\left(\frac{R-1}{R}\right)$ for all $p$ such that $0<p \leq 1$, debt falls over time. Hence, governments that suffer from imperfect credibility, in the sense of being vulnerable to a speculative attack in the future, should run a fiscal policy that is sufficiently tight so as to reduce debt. This result is analogous to that of section 3: because expected devaluation depends on the stock of debt, and 
an attack implying such an expected devaluation happens with probability $p$, there are benefits associated with government saving that are additional to those present in the standard public debt management problem à la Barro (1979).

The expected loss faced by a government following this policy, starting at a stock of debt $b_{t}$ and in a period when no attack has taken place, is given by

$$
L^{f}\left(b_{t}, 0,0\right)=\left(\frac{1}{2}\right)\left(\frac{R-1}{R}\right) \phi(p)\left(R b_{t}\right)^{2}
$$

where $\phi(p)$ is a function given by

$$
\phi(p)=\frac{\rho^{2}\left(\frac{R}{R-1}\right)+R p(1-\rho)^{2} \psi}{1-R(1-p)(1-\rho)^{2}}
$$

One can readily check that $1<\phi(p)<\psi, \phi^{\prime}(p)>0, \phi(0)=1$, and $\phi(1)=R \psi[1+\psi(R-1)]^{-1}>1 .^{16}$

On the other hand, losses suffered by a government that does devalue after not being attacked, starting with some debt $b_{t}$, are given by 19 . Comparing 19 and 33 we have

$$
L^{n d}\left(b_{t}, 0,0\right)-L^{d}\left(b_{t}, 0,0\right)=\left(\frac{1}{2}\right)\left(\frac{R-1}{R}\right)\left\{\phi(p)-\frac{\psi}{(1+\theta \beta)^{2}}\right\}\left(R b_{t}\right)^{2}-c
$$

Given that $\phi(p)>1$, and that earlier we restricted our attention to the case where $\psi<(1+\theta \beta)^{2}$, the term in curly brackets in 35 is positive. Therefore, there is one debt level, call it $b^{*}$, that sets 35 equal to zero. That is the level of debt below which a government that has not been attacked will not choose to foist a surprise devaluation on the public. ${ }^{17}$

What about cases in which an attack does indeed take place? Suppose such an attack happens at time $t$, starting at a stock of debt $b_{t}$. Then, a government that does not devalue at time $t$, and that follows the optimal

\footnotetext{
${ }^{10}$ This last inequality follows from the fact that $\psi>1$.

${ }^{17}$ Notice also that it is clear that $b^{*}<\bar{b}$. This is seen recalling 21 , which defined $\bar{b}$, and also using the fact that $\phi(p)>1$. The intuition for this result is that a government that chooses not to devalue today knows that it may end up devaluing sometime in the future; therefore, its continuation value is lower than it was in the case in which no devaluation was foreseen in the future, and it will only choose to continue (that is, not to devalue) if debt is relatively low.
} 
fiscal policy given that it expects to return to the proposed equilibrium path the following period (this fiscal policy is, quite obviously, the same as in the previous case), suffers an expected loss given by

$$
L^{n d}\left(b_{t}, \beta R b_{t}, 0\right)=\left(\frac{1}{2}\right)\left(\frac{R-1}{R}\right)(1+\theta \beta)^{2} \phi(p)\left(R b_{t}\right)^{2}
$$

Expression 36 is identical to 33, except that the attack at time $t$ increases the government's initial commitments by a factor $(1+\theta \beta)$. Nothing about future optimal behavior changes.

Notice that if at the start of period $t$ the inherited stock of debt was $b_{t}$, at the start of $t+1$ it will be $(1+\theta \beta) R(1-\rho) b_{t}$, where it can be easily shown that $(1+\theta \beta) R(1-\rho)>1$ as long as $p<1$. We know from above that a necessary condition for the government not to devalue is that debt levels be no larger than $b^{*}$.

Hence, for the government's conjecture of a return to the equilibrium path in the next period to be rational, we must have $b_{t} \leq \hat{b} \equiv[1+\theta \beta R(1-\rho)]^{-1}$ $b^{*} .18$

By contrast, if the government devalues in response to the attack it gets $L^{d}\left(b_{t}, \beta R b_{t}, 0\right)$, which is given by 24 with $k=0$. Hence, the relevant comparison involves 24 and 36 :

$$
\begin{aligned}
& L^{n d}\left(b_{t}, \beta R b_{t}, 0\right)-L^{d}\left(b_{t}, \beta R b_{t}, 0\right) \\
= & \left(\frac{R-1}{2 R}\right)\left\{\phi(p)-\frac{\psi}{(1+\theta \beta)^{2}}\right\}(1+\theta \beta)^{2}\left(R b_{t}\right)^{2}
\end{aligned}
$$

which is positive, given our earlier arguments, as long as debt is positive.

We can now proceed to the characterization of the equilibrium, to which correspond the following pair of value functions:

$$
L\left(b_{t}, 0,0\right)=\operatorname{Min}\left\{L^{d}\left(b_{t}, 0,0\right), L^{n d}\left(b_{t}, 0,0\right)\right\}
$$

and

$$
L\left(b_{t}, \beta R b_{t}, 0\right)=\operatorname{Min}\left\{L^{d}\left(b_{t}, \beta R b_{t}, 0\right), L^{n d}\left(b_{t}, \beta R b_{t}, 0\right)\right\}
$$

where, once again, $L^{d}\left(b_{t}, 0,0\right)$ is given by $19, L^{\text {nd }}\left(b_{t}, 0,0\right)$ is given by 33 , $L^{d}\left(b_{t}, \beta R b_{t}, 0\right)$ by 24 with $k=0$, and $L^{\text {nd }}\left(b_{t}, \beta R b_{t}, 0\right)$ by 36 .

\footnotetext{
${ }^{18}$ Note that $b^{*}<\widehat{b}<\bar{b}$.
} 
If $L^{d}\left(b_{t}, 0,0\right)>L^{\text {nd }}\left(b_{t}, 0,0\right)$, so that $L\left(b_{t}, 0,0\right)=L^{\text {nd }}\left(b_{t}, 0,0\right)$, and if $L^{d}\left(b_{t}, \beta R b_{t}, 0\right)<L^{n d}\left(b_{t}, \beta R b_{t}, 0\right)$, so that $L\left(b_{t}, \beta R b_{t}, 0\right)=L^{d}\left(b_{t}, \beta R b_{t}, 0\right)$, we have an equilibrium. Indeed, both of these conditions hold, as we can see from 35 and 37 , if $b_{t} \leq \hat{b}$.

The following summarizes the results of this section:

Proposition 5 (Sunspot Equilibria) If $\psi<(1+\theta \beta)^{2}, k=0$, and debt is such that $b_{t} \leq \hat{b}$, then there exists a sunspot equilibrium in which attacks take place (and succeed in bringing down the peg) with probability $p$. Along this equilibrium path, and as long as there is no attack and corresponding devaluation, debt falls at the speed dictated by 32

Intuitively, if debt is not too large, it pays off for a policymaker who does not experience an attack this period to persevere and not devalue, even though she understands the Central Bank will suffer an attack with probability $p$ next period. The debt threshold under which this is true, $\widehat{b}$, is naturally smaller than $\bar{b}$, the non-devaluation threshold for the case in which the policymaker does not expect to suffer an attack ever in the future. This is the situation depicted in Figure 3.

\section{Conclusions}

This paper extends the logic of the Barro-Gordon framework to a dynamic context in which the level of a state variable (in this case government debt) determines the payoffs available to the government at each point in time. In doing so it provides a full analysis of the intertemporal choices faced by a government that is considering devaluing, and therefore helps in tackling the question "When are fixed exchange rates really fixed?"

The answer if simple: if a country's investors are confident (in the sense of being unlikely to engage in speculative attacks), then debt, broadly understood, has to be sufficiently low; if the country's investors are fickle (in the sense of being prone to panic), then debt has to be even lower. If debt early one is too large, in the sense that it renders the peg vulnerable to selffulfilling attacks, a government that acts optimally would choose to reduce debt. Only then can announced fixed rates be here to stay. 


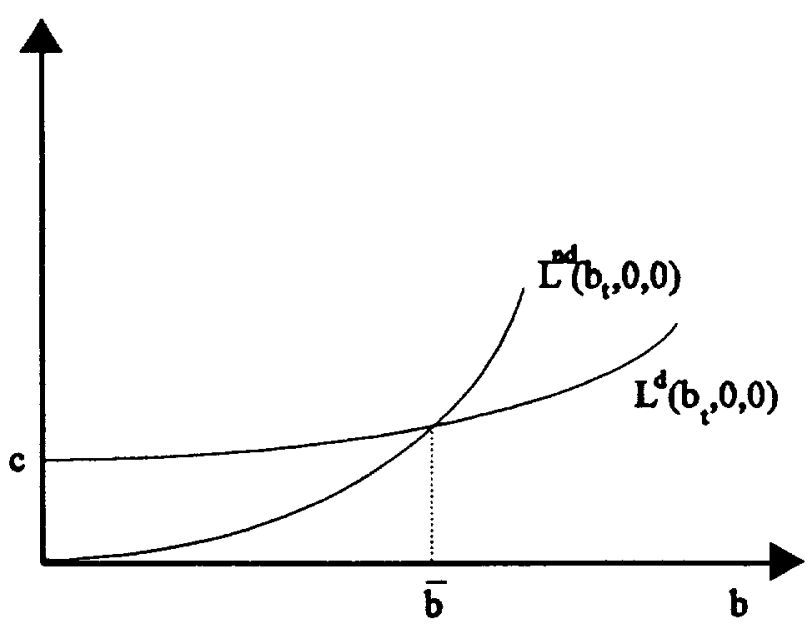

Figure 1

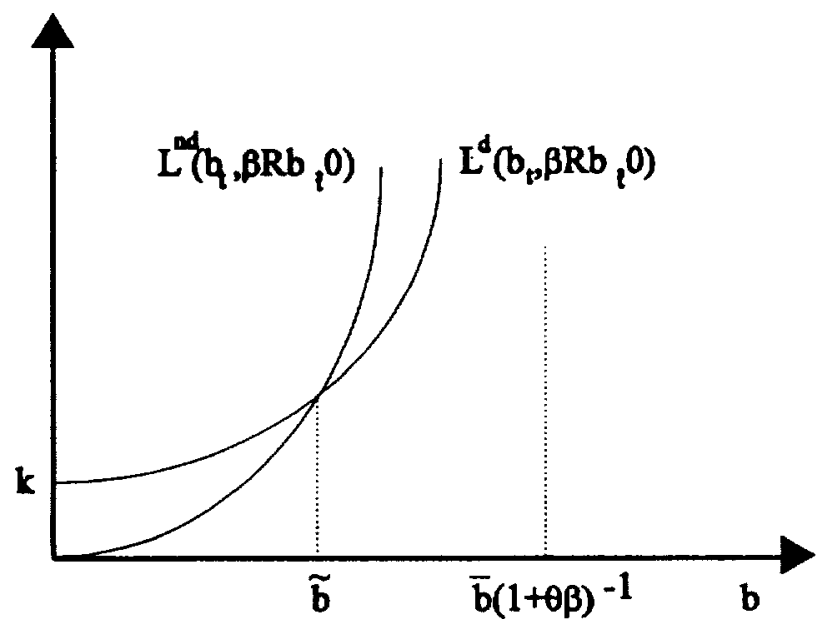

Figure 2

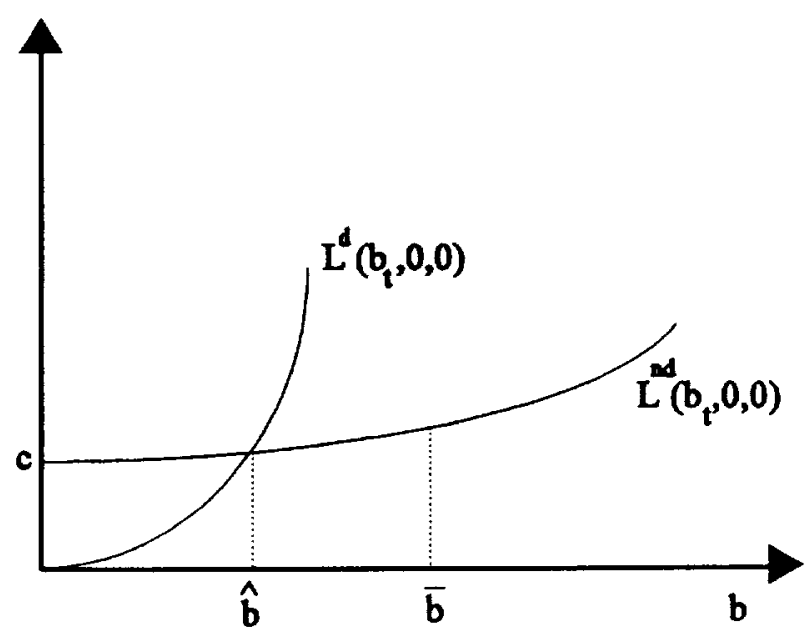

Figure 3 


\section{References}

[1] Agenor, P.R., Bhandari, J., and R. Flood "Speculative Attacks and Models of Balance of Payments Crises" International Monetary Fund Staff Papers, 39, June 1992.

[2] Barro, R. "On the Determination of the Public Debt" Journal of Political Economy, Vol. 87, 1979.

[3] _ _ and D. Gordon "A Positive Theory of Monetary Policy in a Natural Rate Model" Journal of Political Economy, 1983.

[4] Benhabib, J. and A. Velasco "Optimal Taxes and Government Size in an Open Economy" European Economic Review, May 1996.

[5] _. . A. Rustichini and A. Velasco "Public Capital and Optimal Taxes without Commitment" Research Report 96-19, C.V. Starr Center for Applied Economics at NYU, May 1996.

[6] Bensaid, B. and O. Jeanne "The Instability of Fixed Exchange Rate Systems When Raising the Nominal Interest Rate is Costly" Discussion Paper No. 190, LSE Financial Markets Group, July 1994a.

[7] Rules" Mimeo, CERAS-ENPC, November 1994b.

[8] Calvo, G. and P. Guidotti "Credibility and Nominal Debt: Exploring the Role of Maturity in Managing Inflation" IMF Staff Papers, Vol. 37, No. 3, September 1990.

[9] Chari, V.V. and P. Kehoe "Sustainable Plans" Journal of Political Economy, Vol. 98, No. 4, 1990.

[10] Cole, H. and T. Kehoe "Self-Fulfilling Debt Crises" Mimeo, Federal Reserve Bank of Minneapolis, November 1995.

[11] Cukierman, A., M. Kiguel and L. Leiderman "Choosing the Width of Exchange Rate Bands: Credibility vs. Flexibility" CEPR Discussion Paper No. 809, January 1994. 
[12] de Kock, G. and V. Grilli "Fiscal Policies and the Choice of Exchange Rate Regime" The Economic Journal, Vol. 103, March 1993.

[13] Drazen, A. and P. Masson "Credibility of Policies versus Credibility of Policymakers" Quarterly Journal of Economics, 1994.

[14] Edwards, S. "Exchange Rate Anchors and Inflation: A Political Economy Approach" Mimeo, UCLA, 1995.

[15] Fudenberg, D. and J. Tirole, Game Theory, Cambridge: MIT Press, 1992.

[16] Horn, H. and T. Persson "Exchange Rate Policy, Wage Formation and Credibility" European Economic Review 32, No.8, October 1988.

[17] Jeanne, O. "Models of Currency Crises: A Tentative Synthesis with Special Reference to the 1992-93 EMS Crisis" Mimeo, ENPC-CERAS, December 1994.

[18] Klein, M. and N. Marion "Explaining the Duration of Exchange Rate Pegs" NBER Working Paper No.4651, February 1994.

[19] Krugman, P. "A Model of Balance of Payments Crises" Journal of Money, Credit and Banking, 1979.

[20] "Are Currency Crises Self Fulfilling?" Paper presented at the panel meeting of the NBER Macroeconomics Annual, Cambridge, March 1996.

[21] Kydland, F. and E. Prescott "Rules Rather Than Discretion: The Inconsistency of Optimal Plans" Journal of Political Economy Vol. 85, pp. 473-92, 1977.

[22] Obstfeld, M. "Rational and Self-Fulfilling Balance of Payments Crises" American Economic Review, 1986.

[23] _Dynamic Seigniorage Theory: An Exploration" CEPR Discussion Paper No. 519, 1991 .

[24] _Destabilizing Effects of Exchange Rate Escape Claus$\overline{\mathrm{es}} \overline{\mathrm{N}} \overline{\mathrm{N}} \overline{\mathrm{E}} \overline{\mathrm{R}} \overline{\mathrm{R}}$ Working Paper No. 3603, $1991 \mathrm{~b}$. 
[25] et Monetaires, No. 43, 1994.

[26] Ozkan, F. G.. and A. Sutherland "A Currency Crisis Model with an Optimizing Policymaker" Mimeo, University of York, December 1994.

[27] Currency Crisis" The Economic Journalh Vol. 105, March 1995.

[28] Rogoff, K. "The Optimal Degree of Commitment to an Intermediate Monetary Target" Quarterly Journal of Economics Vol. 100, pp. 1169$90,1985$.

[29] Sachs, J., A. Tornell and A. Velasco "The Collapse of the Mexican Peso: What Have We Learned?" Economic Policy, No. 22, 1996

[30] Stokey, N. "Credible Public Policy" Journal of Economic Dynamics and Control, Vol. 15, 1991.

[31] Tornell, A. and A. Velasco "Fixed versus Flexible Exchange Rates: Which Provides More Fiscal Discipline?" NBER Working Paper No. 5108, May 1995.

[32] Velasco, A. "Are Balance of Payments Crises Rational? A Dynamic Game Approach" Mimeo, New York University, 1994. 